\title{
First tomographic observations of gravity waves by the infrared limb imager GLORIA
}

\author{
Isabell Krisch ${ }^{1}$, Peter Preusse ${ }^{1}$, Jörn Ungermann ${ }^{1}$, Andreas Dörnbrack ${ }^{2}$, Stephen D. Eckermann ${ }^{3}$, Manfred Ern ${ }^{1}$, \\ Felix Friedl-Vallon ${ }^{4}$, Martin Kaufmann ${ }^{1}$, Hermann Oelhaf ${ }^{4}$, Markus Rapp ${ }^{2,5}$, Cornelia Strube ${ }^{1}$, and Martin Riese ${ }^{1,6}$ \\ ${ }^{1}$ Forschungszentrum Jülich, Institute of Energy- and Climate Research, Stratosphere (IEK-7), Jülich, Germany \\ ${ }^{2}$ Deutsches Zentrum für Luft- und Raumfahrt, Institut für Physik der Atmosphäre, Oberpfaffenhofen, Germany \\ ${ }^{3}$ E. O. Hulburt Center for Space Research, Naval Research Laboratory, Washington, DC, USA \\ ${ }^{4}$ Karlsruhe Institute of Technology, Institute of Meteorology and Climate Research, Karlsruhe, Germany \\ ${ }^{5}$ Meteorologisches Institut München, Ludwig-Maximilians-Universität München, Munich, Germany \\ ${ }^{6}$ Institut für Atmosphären- und Umweltforschung, Bergische Universität Wuppertal, Wuppertal, Germany
}

Correspondence: Isabell Krisch (i.krisch@fz-juelich.de)

Received: 7 July 2017 - Discussion started: 19 July 2017

Revised: 26 October 2017 - Accepted: 17 November 2017 - Published: 18 December 2017

\begin{abstract}
Atmospheric gravity waves are a major cause of uncertainty in atmosphere general circulation models. This uncertainty affects regional climate projections and seasonal weather predictions. Improving the representation of gravity waves in general circulation models is therefore of primary interest. In this regard, measurements providing an accurate 3-D characterization of gravity waves are needed. Using the Gimballed Limb Observer for Radiance Imaging of the Atmosphere (GLORIA), the first airborne implementation of a novel infrared limb imaging technique, a gravity wave event over Iceland was observed. An air volume disturbed by this gravity wave was investigated from different angles by encircling the volume with a closed flight pattern. Using a tomographic retrieval approach, the measurements of this air mass at different angles allowed for a 3-D reconstruction of the temperature and trace gas structure. The temperature measurements were used to derive gravity wave amplitudes, 3-D wave vectors, and direction-resolved momentum fluxes. These parameters facilitated the backtracing of the waves to their sources on the southern coast of Iceland. Two wave packets are distinguished, one stemming from the main mountain ridge in the south of Iceland and the other from the smaller mountains in the north. The total area-integrated fluxes of these two wave packets are determined. Forward ray tracing reveals that the waves propagate laterally more than $2000 \mathrm{~km}$ away from their source region. A comparison of a 3-D ray-tracing version to solely column-based propagation
\end{abstract}

showed that lateral propagation can help the waves to avoid critical layers and propagate to higher altitudes. Thus, the implementation of oblique gravity wave propagation into general circulation models may improve their predictive skills.

\section{Introduction}

Gravity waves (GWs) are oscillations in wind velocity and temperature with buoyancy as a restoring force (Fritts and Alexander, 2003). They are the main driver of prominent circulation patterns in the mesosphere, such as the wind reversal in the mesosphere-lower thermosphere region (MLT). The exerted drag induces the meridional circulation in the MLT and finally leads to the cold summer mesopause and the warm winter stratopause (Holton, 1982, 1983; McLandress, 1998; Siskind, 2014).

GWs have a strong influence not only on the mesosphere but also on the stratosphere. There, they influence the circumpolar jet and its varying degrees of strength (McLandress et al., 2012; Ern et al., 2016), the tropical quasi-biennial oscillation (QBO) of stratospheric tropical winds and its teleconnections into the extratropical troposphere (Dunkerton, 1997; Kawatani et al., 2010; Ern et al., 2014), and the variability in the strength of the meridional Brewer-Dobson circulation (Alexander and Rosenlof, 2003; Butchart, 2014). These stratospheric circulations then have an impact on near- 
surface seasonal weather and regional climate via dynamical couplings with the troposphere (Scaife et al., 2016; Kidston et al., 2015).

Considering their small scales, the full spectrum of GWs cannot be resolved in general circulation models (GCMs) due to computational issues. Hence, they are simplified in form of parameterizations. Consequences of these GW parameterizations are for example surface temperature uncertainties of up to $2 \mathrm{~K}$ (Sigmond and Scinocca, 2010) and pressure discrepancies of several hPa at polar latitudes (Sandu et al., 2016) in climate projections. Improved weather predictions and climate projections therefore require more advanced parameterization schemes as proposed by various studies (Kim et al., 2013; Bushell et al., 2015; de la Camara and Lott, 2015; Amemiya and Sato, 2016).

One of the strongest simplifications, used for parameterizations, is to assume solely vertical propagation of GWs. However, several modeling studies have highlighted the importance of 3-D propagation of GWs to correctly reproduce the abovementioned circulation patterns (Sato et al., 2009; Preusse et al., 2009; McLandress et al., 2012; Kalisch et al., 2014; Ribstein and Achatz, 2016). Further, GW source distributions and launch parameters, such as propagation direction and wavelength spectrum, are often over-simplified in parameterizations (McFarlane, 1987; Hines, 1997; Alexander and Dunkerton, 1999; Scinocca and McFarlane, 2000; Beres et al., 2005; Richter et al., 2010; Garcia et al., 2017) and need validation by observations (Geller et al., 2013).

To underline the importance of 3-D propagation and validate GW source distributions, measurements are needed that allow for a full 3-D wave characterization including the propagation direction (Alexander et al., 2010). Such a characterization is, in principle, possible from various in situ techniques. Several methods were developed to evaluate data from close-to-vertical profiles taken by radiosondes, dropsondes, or falling spheres. These methods include hodograph analysis (Guest et al., 2000), the Stokes method (Eckermann and Vincent, 1989), or a combination of wind and temperature measurements in a common approach (Wang and Geller, 2003; Zhang et al., 2014). Furthermore, there are multiple techniques based on horizontal traces for example from airplane measurements (Alexander and Pfister, 1995; Fritts et al., 2016; Smith et al., 2016; Wagner et al., 2017) and observations by super-pressure balloons (Boccara et al., 2008; Hertzog et al., 2008). All these methods infer the wave direction via polarization and dispersion relations and do not reveal the 3-D wave structure directly.

First 3-D wave structures from satellite measurements in the stratosphere are presented by Ern et al. (2017) and Wright et al. (2017). However, these studies are based on nadir observations of the Atmospheric Infrared Sounder (AIRS) satellite instrument and are limited by the coarse vertical resolution. This implies that GWs with vertical wavelengths below $15 \mathrm{~km}$ are invisible to the instrument. In the mesosphere, a full wave characterization of small-scale GWs has been achieved with the Middle Atmosphere Alomar Radar System (MAARSY; Stober et al., 2013). For medium-scale GWs in the mesosphere, a full characterization has been derived by combining lidar and airglow imager measurements (Bossert et al., 2015; Lu et al., 2015; Cao et al., 2016). However, all these observations are limited to a few ground-based stations. Further, it is difficult to link observations at altitudes as high as the mesopause region to specific GW sources, which are usually located at much lower altitudes in the troposphere and lower stratosphere. So far no measurement technique existed to measure the 3-D structure of mesoscale GWs in the lower stratosphere.

A novel technique to measure GWs in the upper troposphere-lower stratosphere, i.e., close to the $\mathrm{GW}$ sources, is limb imaging. Limb imaging allows for a 3-D reconstruction of the atmospheric temperature and consequently a full characterization of mesoscale GWs. The development of the Gimballed Limb Observer for Radiance Imaging of the Atmosphere (GLORIA) is the first implementation of such an airborne infrared limb imager (Friedl-Vallon et al., 2014; Riese et al., 2014).

This technique was applied for the exploration of a GW for the first time in a research flight on 25 January 2016 above Iceland. The results of this research flight are presented in this paper. Section 2.1 describes the instrument and the retrieval technique. The results are presented in Sect. 2.2 and subsequently analyzed for GWs in Sect. 3.1. The obtained GW parameters are used for a wave propagation study in Sect. 3.2.

\section{Data and methodology}

\subsection{Measurement technique}

This paper is based on tomographic measurements taken by the infrared limb imager GLORIA on board the German high-altitude and long-range research aircraft (HALO). The aircraft campaign took place from December 2015 to March 2016 with campaign bases in Kiruna, Sweden, and Oberpfaffenhofen, Germany. In total there were 21 research flights performed covering $20-90^{\circ} \mathrm{N}$ and $80^{\circ} \mathrm{W}-30^{\circ} \mathrm{E}$. The scientific targets of this campaign were to demonstrate the use of infrared limb imaging for gravity wave studies (GWEX), to study the full life cycle of a gravity wave (GW-LCYCLE), to investigate the Seasonality of Air mass transport and origin in the Lowermost Stratosphere (SALSA), and to observe the Polar Stratosphere in a Changing Climate (POLSTRACC).

GLORIA combines a Michelson interferometer with a 2$\mathrm{D}$ infrared detector and measures molecular thermal emissions in the spectral range between 780 and $1400 \mathrm{~cm}^{-1}(7.1$ to $12.8 \mu \mathrm{m}$ ). It has a $256 \times 256$ pixels detector. However, to increase the read-out time, only a subset of $48 \times 128$ pixels is used. Thus, 6144 spectra are recorded simultaneously. GLORIA's line of sight aims towards the horizon on the right 
side of the aircraft and measures infrared radiation emitted by molecules in the atmosphere. The point of the line of sight which is closest to the earth surface is called tangent point. Due to the curvature of the earth surface and the atmospheric density profile, the weighting function of the measurement signal has its maximum around this tangent point (Riese et al., 1999). This means that typically most of the measured radiation is emitted around the tangent points, which are located between $5 \mathrm{~km}$ and aircraft flight altitude. The horizontal observation angle of GLORIA can be adjusted from $45^{\circ}$ (right-forward) to $135^{\circ}$ (right-backward) in respect to the aircraft's flight direction. In this way, the instrument can investigate the same air volume from different directions, which allows for a tomographic retrieval scheme (Ungermann et al., 2010; Kaufmann et al., 2015).

The basis of a tomographic retrieval scheme is a fast radiative transfer model. For the retrievals presented in this paper the Juelich Rapid Spectral Simulation Code Version 2 (JURASSIC2; Ungermann et al., 2010) is used. With this radiative transfer model $\boldsymbol{F}(\boldsymbol{x})$ infrared radiances can be calculated directly from an atmospheric state $\boldsymbol{x} \in \mathbb{R}^{n}$. Reconstructing the atmospheric state $\boldsymbol{x}$ from the infrared measurements $\boldsymbol{y} \in \mathbb{R}^{m}$ (the so-called retrieval or inverse modeling) in contrast presents a nonlinear inverse problem, which is solved with an iterative minimization approach (Ungermann et al., 2011, 2015). For this, the cost function

$J(\boldsymbol{x})=(\boldsymbol{F}(\boldsymbol{x})-\boldsymbol{y})^{T} \mathbf{S}_{\epsilon}^{-1}(\boldsymbol{F}(\boldsymbol{x})-\boldsymbol{y})$

has to be minimized. Here $\mathbf{S}_{\epsilon} \in \mathbb{R}^{m \times m}$ represents the covariance matrix of the measurement error $\epsilon$. To get a unique and well-constrained solution to this minimization problem, a regularization term is added to the cost function (Ungermann et al., 2010). This term ensures that the solution is physically reasonable.

As a priori field $\boldsymbol{x}_{\mathrm{a}}$ a temperature field from the European Centre for Medium-Range Weather Forecasts (ECMWF) operational analyses at resolution T1279/L137 was used, which was smoothed in all spatial directions to remove GW signatures. This smoothing was done by applying a low-pass Fourier filter with cutoff wavenumber 18 in zonal direction. In height and latitude direction a Savitzky-Golay (SG) filter (Savitzky and Golay, 1964) was applied with fourth-order polynomials over 11 and 25 neighboring points, respectively. On the one hand, the so generated a priori field improves the convergence speed of the iterative minimization, as this temperature structure is close to the true values due to the high quality of the ECMWF model. On the other hand, the smoothing ensures that any GW signature in the retrieval result does not stem from the used a priori data. If the a priori data were to exert any influence, it would dampen the GW structure.

For the present retrieval we used the spectral ranges listed in Table 1. In these spectral ranges the main emitters are $\mathrm{CO}_{2}$, $\mathrm{CCl}_{4}, \mathrm{HNO}_{3}$, and $\mathrm{O}_{3}$. The volume mixing ratio of $\mathrm{CO}_{2}$ is well known in this altitude range. Therefore, spectral lines of
Table 1. Spectral windows used for the retrieval presented in this paper. The last column indicates the retrieved quantity for each spectral range.

\begin{tabular}{lrl}
\hline & Spectral range $\left(\mathrm{cm}^{-1}\right)$ & Used for \\
\hline 1 & $790.625-792.500$ & temperature \\
2 & $793.125-795.000$ & $\mathrm{CCl}_{4}$ \\
3 & $796.875-799.375$ & $\mathrm{CCl}_{4}$ \\
4 & $883.750-888.125$ & $\mathrm{HNO}_{3}$ \\
5 & $892.500-896.250$ & $\mathrm{HNO}_{3}$ \\
6 & $900.000-903.125$ & $\mathrm{HNO}_{3}$ \\
7 & $918.750-923.125$ & $\mathrm{HNO}_{3}$ \\
8 & $956.875-962.500$ & temperature \\
9 & $980.000-984.375$ & temperature, $\mathrm{O}_{3}$ \\
10 & $992.500-997.500$ & temperature, $\mathrm{O}_{3}$ \\
11 & $1000.625-1006.250$ & temperature, $\mathrm{O}_{3}$ \\
12 & $1010.000-1014.375$ & temperature, $\mathrm{O}_{3}$ \\
\hline
\end{tabular}

$\mathrm{CO}_{2}$ are used effectively for the retrieval of temperature. Tomographic reconstructions of the 3-D temperature distribution and the mixing ratios of $\mathrm{CCl}_{4}, \mathrm{HNO}_{3}$, and $\mathrm{O}_{3}$ in the upper troposphere and lower stratosphere were achieved. However, a discussion of the trace gas distributions exceeds the scope of this paper.

An error analysis of the retrieval was performed following the methods described in Ungermann et al. (2015). The precision (noise error) is below $0.05 \mathrm{~K}$ and the accuracy, which includes misrepresented background gases, uncertainties in spectral line characterization, uncertainties in instrument attitude, and calibration errors, is on the order of $0.5 \mathrm{~K}$.

The horizontal and vertical resolutions can be defined by the axes of the smallest ellipsoid containing all elements of the averaging kernel larger than half the maximum. Accordingly, in the middle of the performed hexagonal flight path, the vertical resolution is around $200 \mathrm{~m}$ and the horizontal resolution around $20 \mathrm{~km}$.

The time needed to accomplish the hexagon was about $2 \mathrm{~h}$. During this time 2200 infrared images and corresponding spectra were taken. The presented tomographic retrieval represents a temporal mean over all these measurements.

\subsection{Research flight above Iceland}

On the measurement day 25 January 2016, a southerly wind made landfall on the southern coast of Iceland (Fig. 1), thus exciting mountain waves. These waves were predicted by the ECMWF forecast to be stationary above Iceland for more than $6 \mathrm{~h}$. Above $10 \mathrm{~km}$ altitude the zonal wind increased drastically with height and turned from southerly to southwesterly direction. This created a strong vertical wind shear, which influenced the propagation of the excited mountain waves. The wave structure over eastern Iceland was encircled by a hexagonal flight pattern with $460 \mathrm{~km}$ diameter between 10:00 and 12:00 UTC (Fig. 2). The aircraft flight altitude dur- 

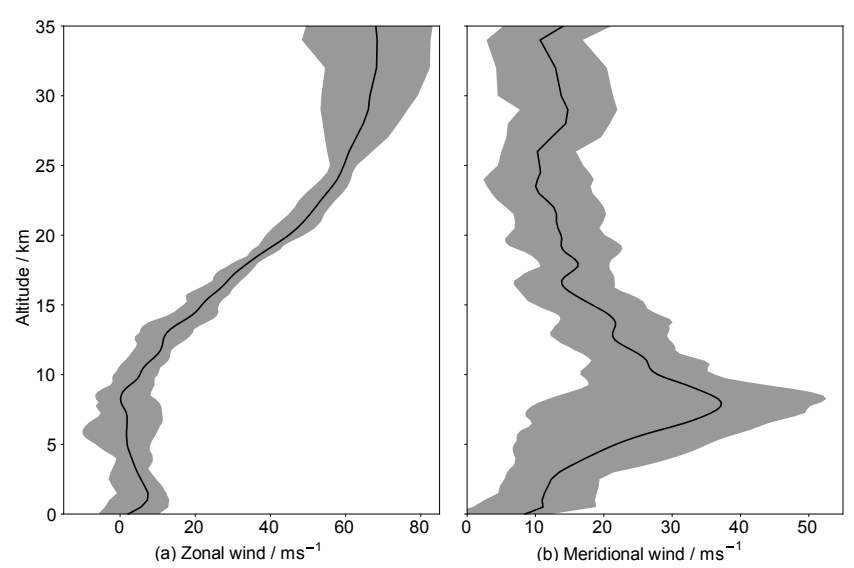

Figure 1. Mean zonal and meridional wind profiles from ECMWF operational analyses T1279/L137 above Iceland and the measurement region at 12:00 UTC on 25 January 2016. The grey area marks the spread of the wind profiles in this area.

ing this time was between 12.5 and $13.5 \mathrm{~km}$. Towards low altitudes, the GLORIA measurements were limited by clouds reaching up as far as 9 to $10.5 \mathrm{~km}$. Before the hexagon a linear flight through the wave field was performed to collect in situ data at flight altitude and to release dropsondes.

For the GLORIA retrieval only the measurements taken between 10:00 and 12:00 UTC have been taken into account. To identify GWs in the retrieved 3-D temperature field, the large-scale temperature background, which is caused by the balanced flow and the stratification of the atmosphere, has to be separated from the smaller-scale temperature variations caused by the GWs. This was done through applying SG filters with third-order polynomials over 25,60 , and 60 neighbouring points in vertical, zonal, and meridional direction. The values of these polynomials at the respective points are treated as temperature background. The remaining temperature residuals clearly reveal the complex structure of the wave field, which is demonstrated in 3-D in Fig. 2.

In Fig. 3, horizontal and vertical cross sections through the measurement volume are presented. They show how the wave structure varies with height and horizontal location. For instance, the wave fronts directly above Iceland $\left(64-65.5^{\circ} \mathrm{N}\right.$ and $14-18^{\circ} \mathrm{W}$ are aligned east-west and tilted southwards against the prevailing southerly wind (Fig. 1). Further to the northeast $\left(65-67^{\circ} \mathrm{N}\right.$ and $\left.10-14^{\circ} \mathrm{W}\right)$, the horizontal orientation of the wave fronts turns more into southwest to northeast. The horizontal wavelength varies inside the hexagon from 100 up to $350 \mathrm{~km}$. The vertical wavelength of the waves is between 3 and $6 \mathrm{~km}$. The temperature residuals range from $\pm 4 \mathrm{~K}$ (in the southwest of the hexagon at an altitude of $12 \mathrm{~km}, 64-65.5^{\circ} \mathrm{N}$, and $14-18^{\circ} \mathrm{W}$ ) down to $\pm 1 \mathrm{~K}$ (in the smaller-scale waves in the northwestern part of the hexagon at $66-68^{\circ} \mathrm{N}$ and $16-20^{\circ} \mathrm{W}$ ).

Figure 4 shows a comparison of the retrieval results with in situ measurements and ECMWF operational analyses with
T1279/L137 resolution. The retrieval results and model data were interpolated onto the in situ measurement locations. The GLORIA measurements agree well with the in situ measurements. Some very small scales are beyond the spatial resolution of GLORIA. The ECMWF analysis catches the main variations, but the temperature oscillations are not as strong as in reality. GLORIA can better reproduce peaks as, for example, the one around 10:40 UTC. This comparison underlines the high quality of the GLORIA measurement data.

\section{Results}

\subsection{Sinusoidal wave fits}

In order to further interpret the GW structure and fully characterize it, wave parameters are derived using a small-volume few-wave decomposition technique (Lehmann et al., 2012). The algorithm performs 3-D sinusoidal fits in small data cubes. In such a way, the wave amplitude, horizontal and vertical wavelengths, and 3-D wave direction can be derived. In contrast to a Fourier transform, this technique allows for the characterization of waves with wavelengths larger than the cube size (up to a factor of 2.5 times the cube size). Due to the prevailing wavelength range in our measurements (see Fig. 2), a cube size of $160 \mathrm{~km} \times 160 \mathrm{~km} \times 3.6 \mathrm{~km}$, containing 4900 data points, was chosen. The fitted parameters are the $3-$ $\mathrm{D}$ wave vector $\boldsymbol{k}=(k, l, m)$ and the amplitude (Fig. 5c). Horizontal and vertical wavelengths and the horizontal wave direction were calculated from the wave vector $\boldsymbol{k}$ and shown in Fig. 5a, b, and e, respectively. Figure 5f shows the orography of Iceland. The main mountain ridge is oriented in east-west direction. As expected for a mountain wave, the horizontal wave direction (Fig. 5e) is perpendicular to the ridge orientation. A discussion of relevant effects for the uncertainty of the fitted parameters and the resulting confidence intervals is given in Appendix A.

A key quantity of GWs is the vector of vertical flux of horizontal pseudo-momentum (short GW momentum flux, GWMF):

$\boldsymbol{F}_{\mathrm{ph}}=\frac{1}{2} \rho \frac{\boldsymbol{k}_{\mathrm{h}}}{m}\left(\frac{g}{N}\right)^{2}\left(\frac{\hat{T}}{T}\right)^{2}$,

where $\rho$ represents the air density, $\boldsymbol{k}_{\mathrm{h}}=(k, l)$ the horizontal and $m$ the vertical component of the wave vector, $g$ the standard gravity, $N$ the buoyancy, $T$ the background temperature, and $\hat{T}$ the temperature amplitude (Ern et al., 2004). Low and high frequency terms are omitted here due to simplicity. Deviations from the full equations derived by Ern et al. (2004) are less than $1 \%$ in the observational range of GLORIA. For a full discussion of the relevance of all correction terms see the supporting information in Ern et al. (2017).

Integrating the GWMF over the horizontal extent of a GW event leads to the total momentum, which determines the 


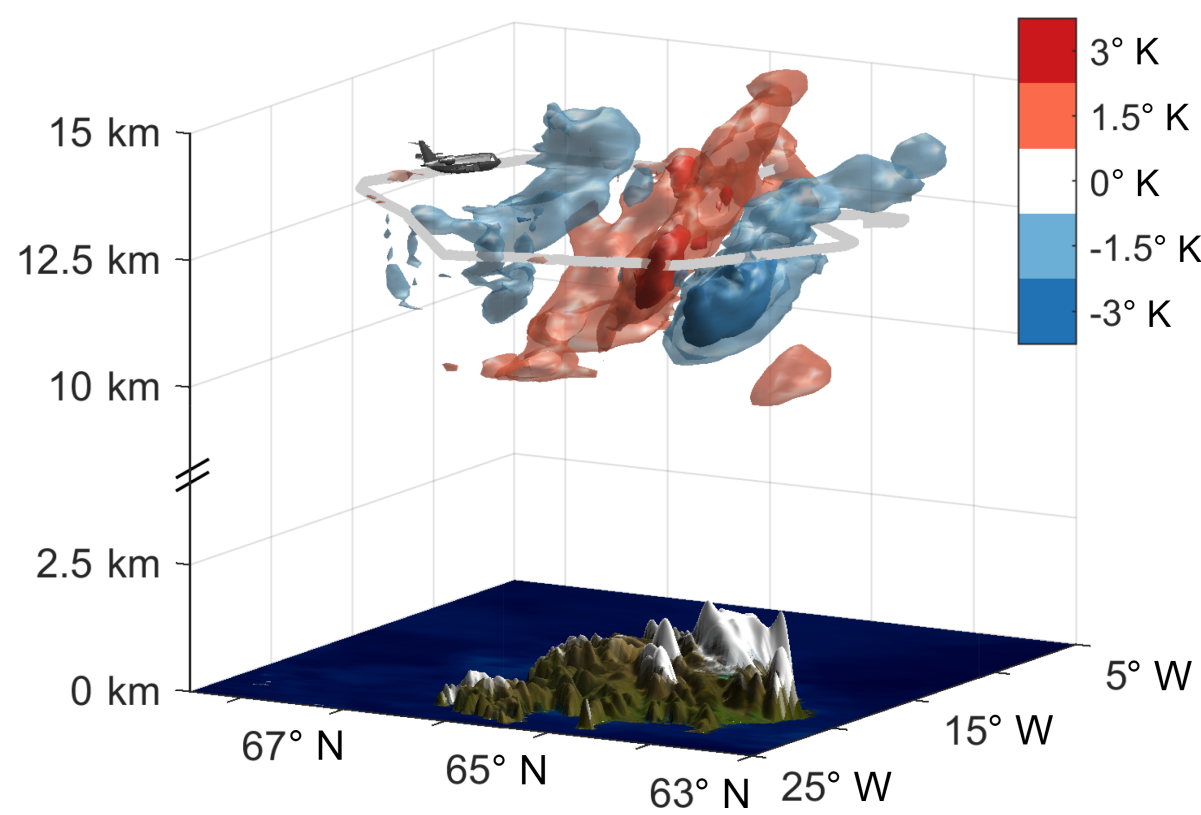

Figure 2. Tomographic retrieval of the temperature field for the research flight on 25 January 2016, over Iceland. Shown are isosurfaces of the temperature residual. The grey line around the retrieved 3-D pattern indicates the flight path. A video showing the retrieval from all sides can be found online (Krisch, 2017a).
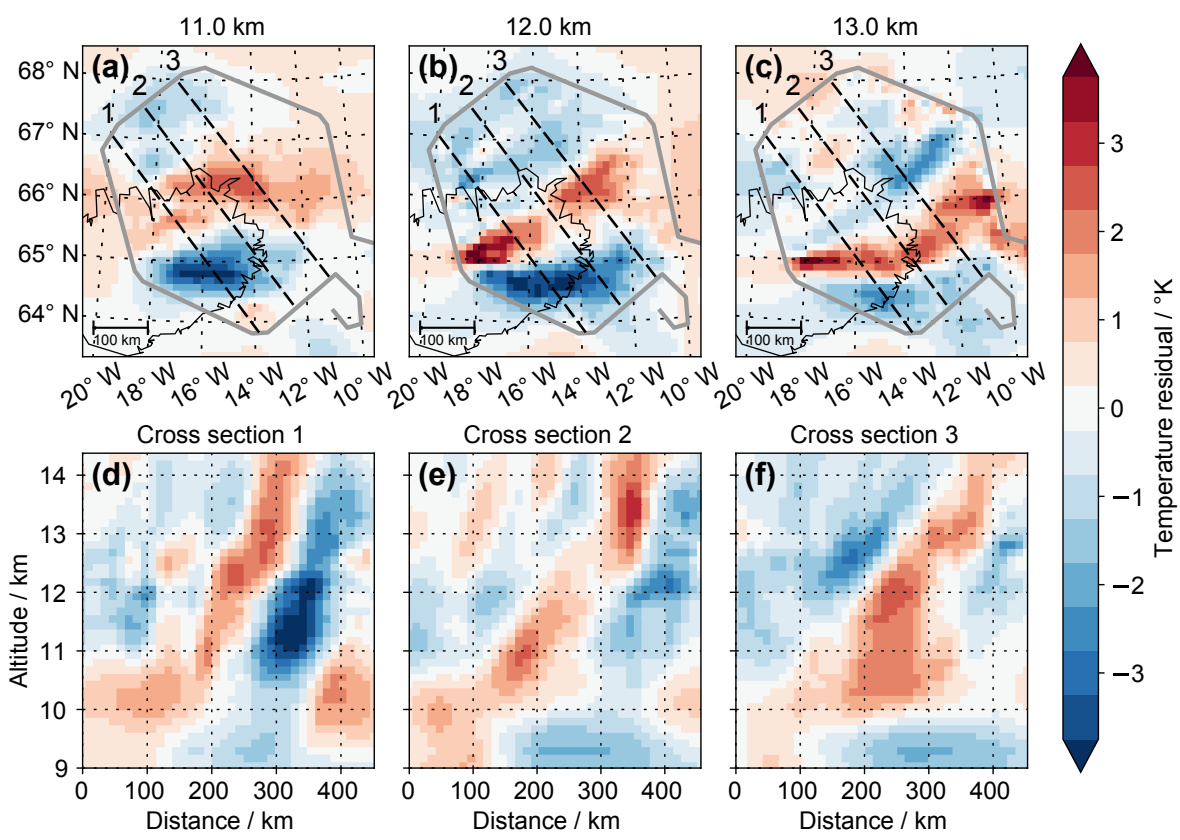

Figure 3. Horizontal (a-c) and vertical (d-f) cross sections through the 3-D volume shown in Fig. 2. The grey line marks the flight path. The locations of the vertical cross sections are indicated by numbered dashed lines.

maximal drag this GW event can exert on the background flow in coupling and dissipation processes. The fitted wave parameters in Fig. 5a-c are used to calculate the GWMF (Fig. 5d). The horizontal distribution of the GWMF clearly highlights two distinct wave packets: one with local GWMF of up to $50 \mathrm{mPa}$ north of $66.2^{\circ} \mathrm{N}$ and one with local GWMF of up to $100 \mathrm{mPa}$ south of $66.2^{\circ} \mathrm{N}$. The GLORIA observations provide the horizontal variations of GWMF at $11.5 \mathrm{~km}$ altitude. This allows us to integrate over the corresponding area of the two events and calculate the total momentum, a measure for the maximal drag this GW event can exert on the background flow in coupling and dissipation processes. 


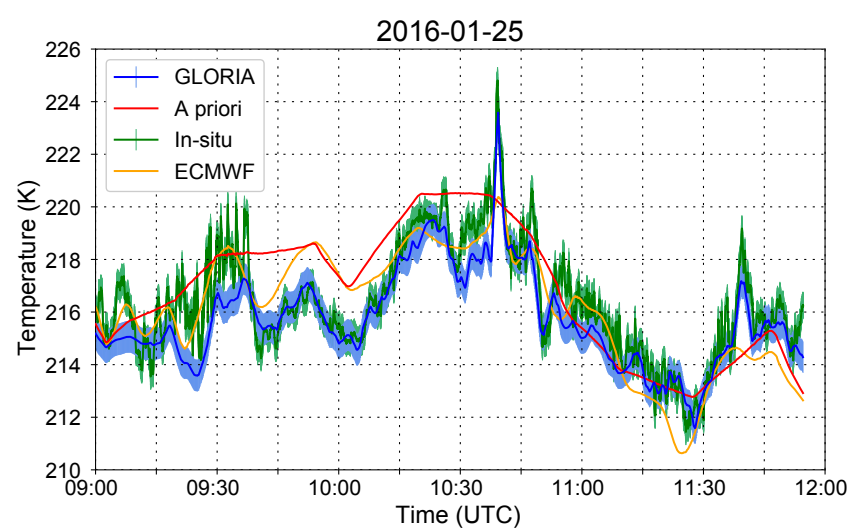

Figure 4. A comparison of the GLORIA retrieval results to in situ temperature measurements and ECMWF operational analyses T1279/L137 at 12:00 UTC. The GLORIA retrieval and the ECMWF data were interpolated in space onto the flight path.

This is a main advantage with respect to 1-D wind observations, which can provide peak GWMF values but not the area for which these values are valid. The wave packet further south has a total momentum of $2.7 \mathrm{GN}$, the second wave packet further north only $0.4 \mathrm{GN}$. The total momentum of all the measured GWs above Iceland is $3.1 \mathrm{GN}$.

To classify this event, a comparison of all GW events in January 2016 has been performed in the 6-hourly operational analyses of ECMWF. First the temperature background was isolated, as described in Sect. 2.1 for the a priori field, and subtracted from the original field. The remaining temperature residuals were analyzed for GWs using the 3-D sinusoidal fit algorithm described above. The GWMFs for all cubes were calculated. The GWMFs from all 124 analyses fields were combined to obtain the probability of GW occurrence (Fig. 6). Here, all GWMF values were considered independent of the horizontal and vertical wavelengths. Removing wavelengths larger than 2.5 times the cube size in order to filter less significant fits (not shown) induced no major changes in the general shape of the distribution. This indicates that GW events with less certain fits do not bias the probability distribution.

For the GW event over Iceland similar GWMF magnitudes were determined from the ECMWF analyses and from the GLORIA measurements. Thus, a comparison of the measurement results with the occurrence probability determined from the ECMWF analyses seems reasonable. According to Fig. 6 the measured GW event can be classified as a very strong case since the sum of all occurrence probabilities of stronger events is well below $1 \%$. This occurrence frequency is in good agreement with Alexander et al. (2010), Hertzog et al. (2012), and Podglajen et al. (2016), who present satellite and super-pressure balloon measurements at slightly higher altitudes.

\subsection{Wave propagation with GROGRAT}

In order to identify the GW source, we used the Gravity wave Regional Or Global RAy Tracer (GROGRAT; Marks and Eckermann, 1995). GROGRAT describes the propagation of wave packets based on linear wave theory. Backward ray tracing has been used in previous studies to locate $\mathrm{GW}$ sources (Preusse et al., 2014; Pramitha et al., 2015). In order to initialize a ray tracer, the wave must be fully characterized. This capability is the main improvement of the GLORIA observations compared to previous remote sensing observations of temperature. GW parameters obtained from single vertical temperature profiles led to a cone of potential source regions instead of a precise source location (Gerrard et al., 2004). This is the reason why GWs derived from conventional limb scanner measurements have not been interpreted in terms of backward ray tracing. Only the 3-D nature and accuracy of the GLORIA measurements allow backtracing to the precise source location. This is further highlighted by the error analysis presented in Appendix A.

In the error analysis, a systematic low bias of the vertical wavelengths was found, which is caused by the sinusoidal fit (Appendix A). Therefore, the vertical wavelengths from the sinusoidal fits were scaled by a factor 1.1, according to the determined bias, before being used for the ray tracing. For the propagation of GWs in a ray-tracing model temporally and spatially varying background temperature and wind fields are needed, which were obtained from ECMWF operational analyses.

Figure 7 shows the backward ray traces of the measured GWs from their measurement position (black crosses) down to the source location (red dots). The measurement position has been defined as the center point of the sinusoidal fitting cube. The strength of the GW is expressed by the size of the red dots, which has been chosen according to the GWMF at the source location. These GWMF values are conservative estimates, as the backward ray tracing cannot account for dissipation processes. The source locations of the GWs, and in particular those of the highest GWMF, gather around the main mountain ridge of Iceland. The GWs are, thus, likely to have been excited by the southerly wind approaching these mountains. The ray traces from the wave packet measured further in the north partly stop in the north of the island at single mountain peaks.

As can be seen in Fig. 7c, the ray traces need between 3 and $6 \mathrm{~h}$ to reach the ground. This is in good agreement with a vertical group velocity of 2 to $3 \mathrm{~km} \mathrm{~h}^{-1}$, which has been calculated from the measurements. Hence, the GWs are probably excited roughly $6 \mathrm{~h}$ before the measurements were taken.

Forward ray tracing is used to examine the propagation of the GWs away from the measurement location (Fig. 7b). On the measurement day, the southerly wind turned into a strong westerly direction above $10 \mathrm{~km}$, creating a strong vertical wind shear. In this wind shear the GWs started to propagate eastward. This is confirmed by the measurements: at $11 \mathrm{~km}$ 

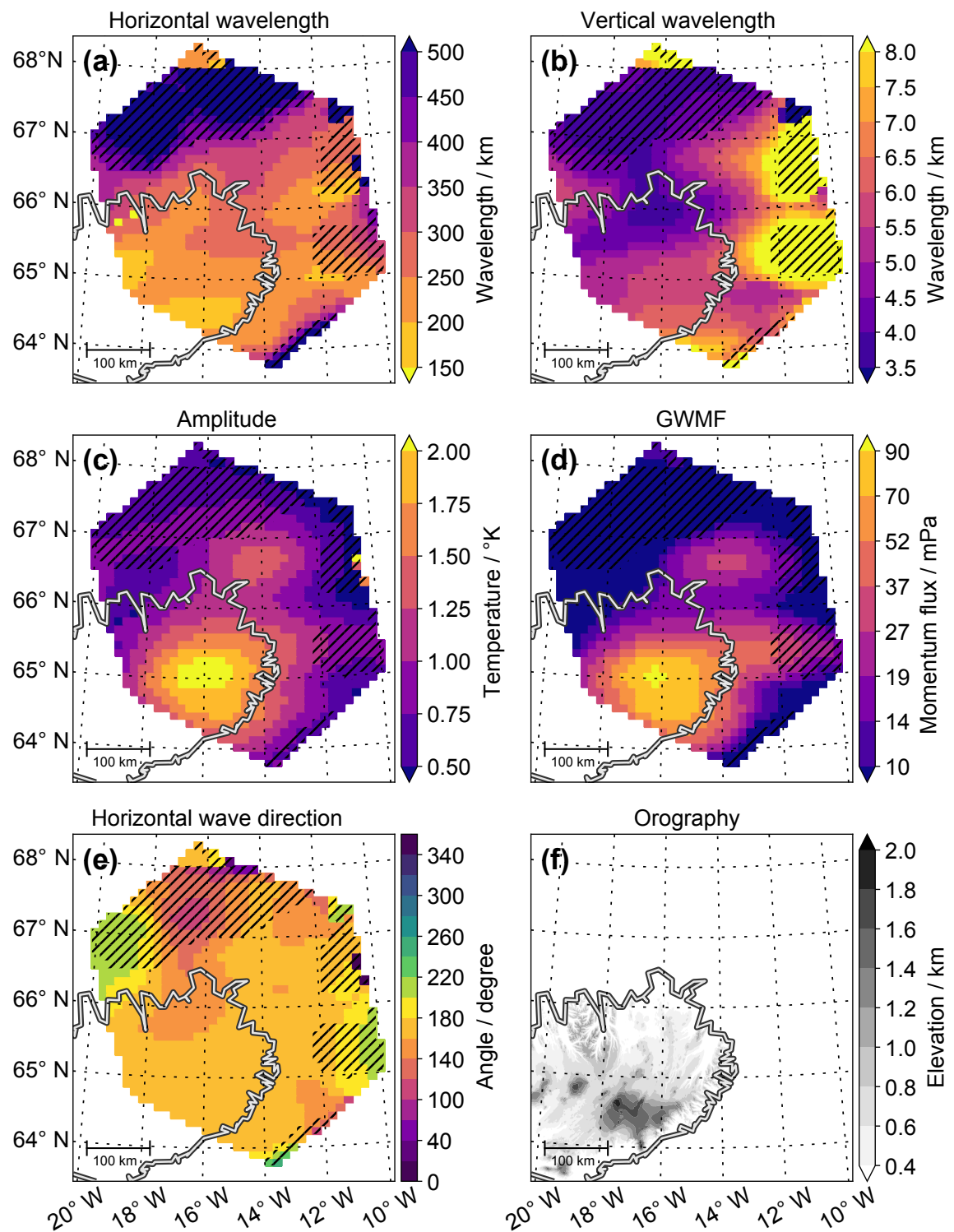

Figure 5. Three-dimensional sinusoidal wave fit of the GLORIA measurements in fitting cubes of $160 \mathrm{~km} \times 160 \mathrm{~km} \times 3.6 \mathrm{~km}$ at a center height of $11.5 \mathrm{~km}$. Nonsignificant fitting results with wavelengths above 2.5 times the cube size are hashed. These parameters are used to drive the GROGRAT model, the results of which are shown in Fig. 7. Panel (e) shows the direction of the horizontal wave vector. Eastward direction corresponds to $90^{\circ}$ and southward direction to $180^{\circ}$.

(Fig. 3a) the GWs are mainly located above the eastern part of Iceland, while at $13 \mathrm{~km}$ (Fig. 3c) the wave fronts already stretch far across the ocean. The waves require about 1 day to propagate to an altitude of $20 \mathrm{~km}$ (Fig. 7c). At the same time, they travel horizontally more than $2000 \mathrm{~km}$ (Fig. 7b). Over eastern Europe, the GWs are refracted due to a horizontal wind shear and, thus, change their horizontal wave vector from southward to westward. This allows the waves to quickly propagate upward into the westerly wind in the mid-stratosphere.
To mimic a typical GW parameterization scheme used in GCMs (McLandress, 1998), a second GROGRAT run (1DGROGRAT) was performed with solely vertical propagation, time-independent background, and a horizontal wave direction constant with respect to altitude. In contrast to the full GROGRAT version (Fig. 7c), where the GWs propagate into the mid-stratosphere, the GWs in the simplified version dissipate below $20 \mathrm{~km}$ (Fig. 7d). Two processes might play a significant role here: first, in the 1-D GROGRAT version the GWs are not refracted and the wave vectors do not change its horizontal orientation with altitude. The westerly back- 


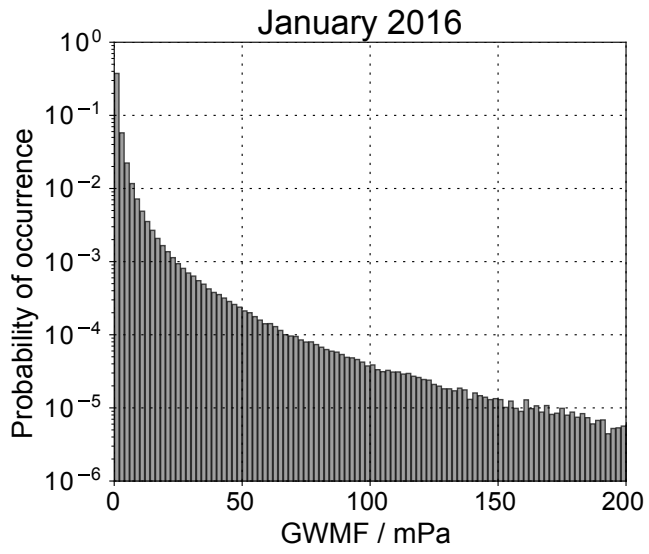

Figure 6. Probability of occurrence for GWs with specific momentum flux at $11.5 \mathrm{~km}$ altitude in a latitude band between 60 and $70^{\circ} \mathrm{N}$ in January 2016 calculated from 6-hourly ECMWF operational analyses fields.

ground winds at higher altitudes do not favor the propagation of GWs with wave vectors perpendicular to the wind direction. Second, in the full GROGRAT run, the GWs propagate horizontally away from the source. Hence, the GWs avoid the critical level positioned above the source location and more GWMF is transported to higher altitudes. Global mountain wave modeling (Xu et al., 2017) suggests that this effect may prevail also on a global basis.

Neither a realistic orientation of the wave vector nor oblique GW propagation is incorporated in GW parameterizations used in current climate and weather prediction models (McLandress, 1998; Alexander and Dunkerton, 1999; Richter et al., 2010; McLandress et al., 2012; Garcia et al., 2017). However, both processes are context of several studies aiming to improve GW parameterizations (Preusse et al., 2009; Sato et al., 2009; Kalisch et al., 2014; Amemiya and Sato, 2016; Ribstein and Achatz, 2016; Garcia et al., 2017). The present paper provides a strong motivation to finally implement these processes in current climate and weather prediction models, especially as this could close gaps of GWMF in regions with sparse sources (McLandress et al., 2012) and reduce the cold-pole bias of climate and weather prediction models in the lower stratosphere (Garcia et al., 2017).

\section{Conclusions}

In this paper, we presented the first tomographic measurements of temperature perturbations induced by a GW event. The 3-D measurements recorded by GLORIA, the first airborne implementation of a novel limb imaging technique, enabled the deduction of direction-resolved GWMF and the identification of two distinct wave packets. The retrieved 3$\mathrm{D}$ wave vectors were used as input in the ray-tracing model GROGRAT, which highlighted the orography of Iceland as
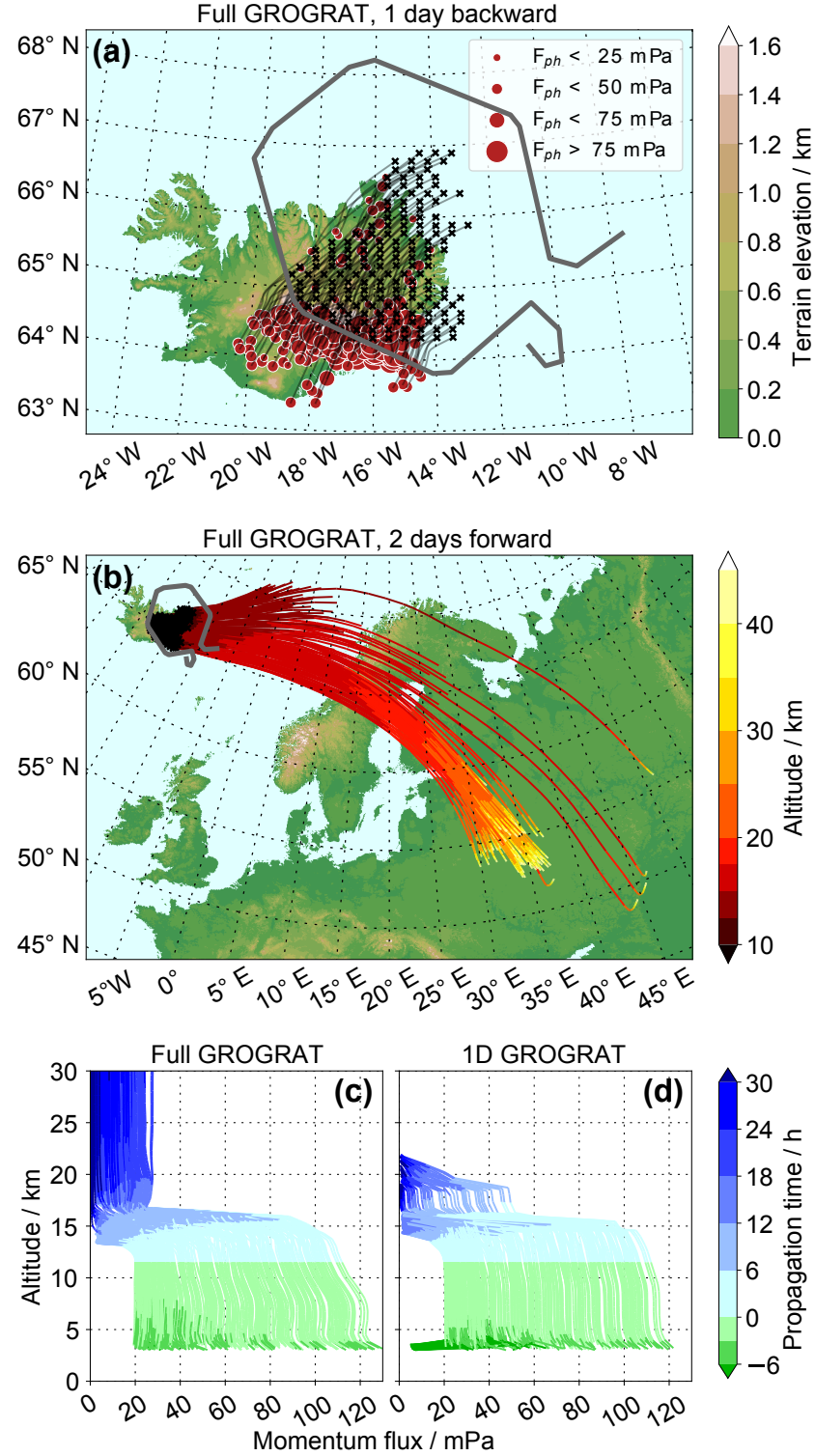

Figure 7. Ray traces calculated using the GROGRAT model. The starting positions of the rays are marked with black crosses and the grey line indicates the flight path. The size of the red circles in panel (a) indicates the GWMF at the end of the ray. Panel (a) shows the backward ray traces and panel (b) the forward ray traces, all starting at the measurement locations. Panels (c) and (d) show the change of GWMF with height for a full 4-D GROGRAT (c) model run and a solely vertical 1-D run (d).

the most likely GW source. Furthermore, upward from $11 \mathrm{~km}$ the wave packets propagate obliquely as is seen from the observation and reproduced by the ray tracer. A comparison between the full GROGRAT model and a simplified 1-D version indicated the relevance of oblique propagation for the GWMF deposition height. In the simplified version, all GWs deposited their momentum at an altitude of around $20 \mathrm{~km}$, whereas the GWs in the full version were able to ver- 
tically propagate to the top of the model at $45 \mathrm{~km}$ and horizontally more than $2000 \mathrm{~km}$ away from their source, thus redistributing GWMF significantly. Given that weather prediction and climate models routinely use 1-D models of GW propagation, the present findings demonstrate that considering 3-D propagation could lead to significant improvements in weather forecasting and climate prediction.
Data availability. The tomographic retrieval data are available from the HALO database (Krisch, 2017b). A video of the retrieved 3-D wave structure is provided online (Krisch, 2017a). 


\section{Appendix A: Error analysis}

In this section the effects of different errors onto the raytracing results presented in Sect. 3.2 are discussed. These errors may, in principle, be caused during each of the three main processing steps: temperature retrieval, background removal, and sinusoidal wave fits (S3D). Retrieval errors can be divided into precision and accuracy (see Sect. 2.1). Due to the high number of independent data in each S3D cube, the precision error (mainly due to noise) can be neglected, in particular since in this paper only GW events with amplitudes above a threshold of $0.5 \mathrm{~K}$ are considered. The error sources which lead to the accuracy error are systematic and slowly varying. Thus, their impact is mostly mitigated by the background removal.

The background removal separates the data into largescale variations and small-scale fluctuations, the latter interpreted as GWs. The main effect of an unfavorably tuned background removal would be to eliminate real GWs. However, it would not introduce errors in the fitted wave vectors. Thus, this has to be considered in a comparison with other data but is not included in the further error discussion.

The third step, the S3D method, is based on the assumption that the fitting volume is filled by a homogeneous wave with a constant wave amplitude and a constant wave vector over the fitting volume. The discussion in Sects. 2.2 and 3.1 demonstrates that this assumption is only valid to a certain degree. In particular, we notice that the direction of the horizontal wave vector and the vertical wavelength change with height as the wave is refracted by a changing background wind.

We use the results of the ray tracer to estimate errors due to this change over height within the fitting volume. In Fig. A1a, c, and e the instantaneous value $\xi_{z=11.5}$ at the middle point of the fitting volume of each individual ray is compared to an average value $\bar{\xi}$ over the full height range of the S3D fitting volume (comparable to the S3D fitting result); here $\xi$ stands for either the vertical or horizontal wavelength or the horizontal wave direction. The mean vertical wavelength shows a systematic low bias of around $10 \%$ compared to the instantaneous value in the middle (Fig. A1a). This effect is taken into account and all vertical wavelengths from the sinusoidal fit (Sect. 3.1) are scaled with a factor of 1.1 before being used in the ray-tracing analysis (Sect. 3.2). For the horizontal wavelength (Fig. A1c) and the horizontal wave direction (Fig. A1e) no systematic bias could be identified.

As mentioned before, the accuracy with which the input wave parameters $\xi$ are determined is of high importance. This is highlighted through varying the values $\xi$ by factor $\epsilon_{\xi}$ and comparing the ray-tracing results with a reference run. The variations $\epsilon_{\xi}$ for the vertical wavelength and the horizontal wave direction are chosen to be half the difference of the wave parameters at the upper $\left(\xi_{z=\max }\right)$ and lower $\left(\xi_{z=\min }\right)$ boundary of the S3D fitting volume as determined by the ray-tracing reference run (Fig. A1b, f). The horizon-
Table A1. Error estimates for the wave parameters inferred by the S3D method based on the change of the parameters over the extent of the fitting cube.

\begin{tabular}{ll}
\hline Error estimate of the vertical wavelength & $\pm 17 \%$ \\
Error estimate of the horizontal wavelength & $\pm 15 \%$ \\
Error estimate of the horizontal wave direction & $\pm 5.5^{\circ}$
\end{tabular}

tal wavelength does not change much over the height of the fitting volume (Fig. A1d). However, Figs. 3 and 5 indicate a significant variation of the horizontal wavelength over the horizontal extent of the fitting volume. Hence, for the error estimate ray-tracing calculations we chose an error value of $\pm 15 \%$ as estimate for the horizontal variation of the horizontal wavelength within the S3D fitting volume. In Table A1 the used error estimates for the three wave parameters are summarized.

The results of the backtracing runs with wave parameters varied by the error estimates in Table A1 are shown in Fig. A2. Longer vertical wavelengths (Fig. A2c, d) lead to more northward located sources, while rays from shorter vertical wavelengths (Fig. A2b) end southward, i.e., upstream of Iceland over the ocean. This is due to the fact that longer vertical wavelengths are associated with higher horizontal phase velocities and hence higher horizontal group velocities. Accordingly, in the case of shorter vertical wavelengths the waves are not able to compensate the background wind velocity and would origin from an upstream source. Actually, we find that the inferred bias $(10 \%$ larger values for the vertical wavelengths), when corrected, improves the match of the ray positions with the topography (Fig. A2c).

The horizontal wave direction has similar impact: When the wave is turned more into the southeasterly background flow (Fig. A2h) the ray paths are more vertically oriented and therefore reach the ground closer to the measurement volume. When they are turned away from the background wind (Figure A2g), the intrinsic group velocity and the background wind are at an angle, the intrinsic group velocity does not fully compensate the background wind, and the waves cover a larger horizontal distance reaching onto the ocean upstream of Iceland.

Similar variations for the forward ray traces are shown in Fig. A3. In all cases except for shorter vertical wavelengths, a major group of ray traces reaches the model top at $45 \mathrm{~km}$ altitude (white dots); i.e., our main findings presented in Sect. 3.2 are robust.

The error estimates demonstrate that a correct identification of the GW source is only feasible for highly accurate wave characterization, such as achieved here thanks to the high spatial resolution and accuracy of GLORIA 3-D temperature measurements. 

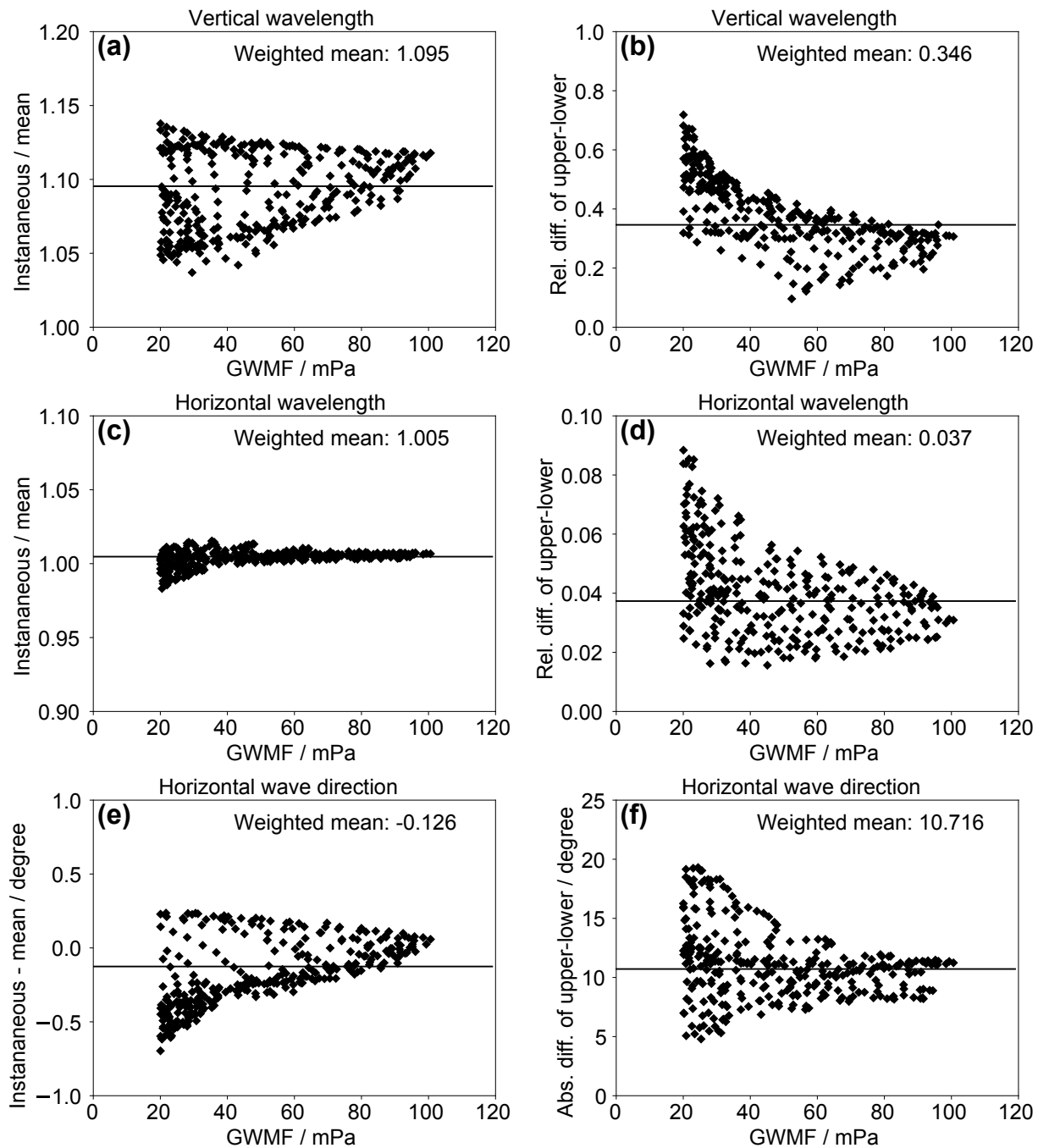

Figure A1. Comparison of mean values over the whole S3D fitting volume and instantaneous values in the middle for different wave parameters $(\mathbf{a}, \mathbf{c}, \mathbf{e})$ and variation of wave parameters from the lower to the upper boundary of the S3D fitting volume (b, d, f). For all graphs GWMF weighted means are calculated and depicted as black lines. 

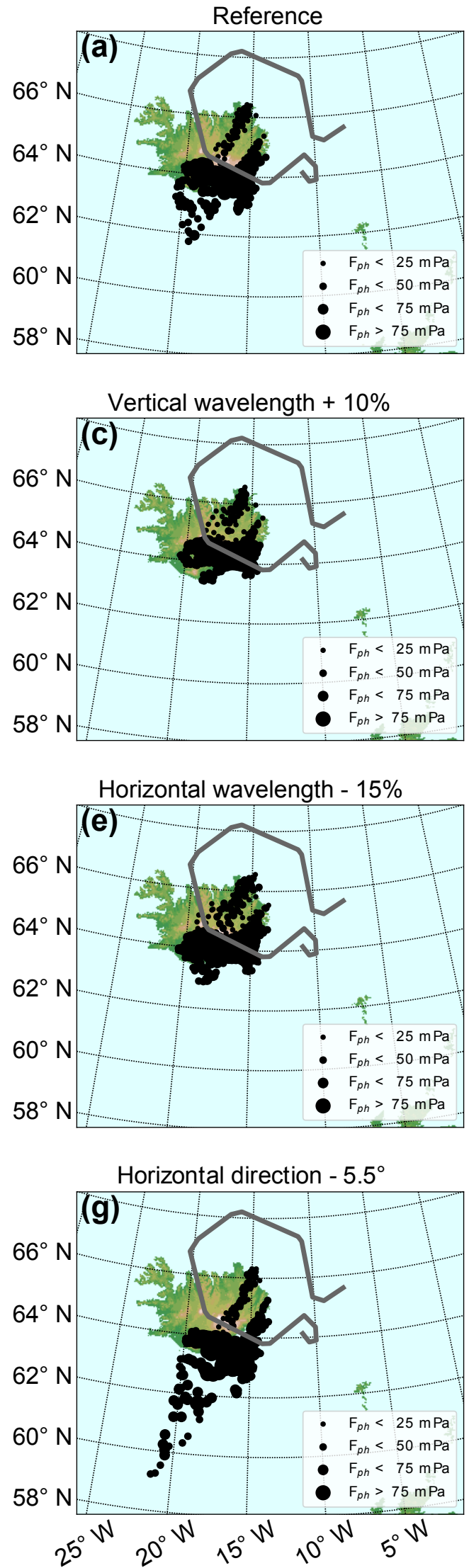

Vertical wavelength $-17 \%$

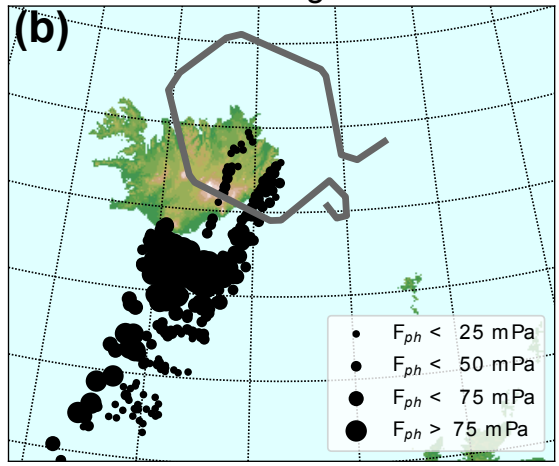

Vertical wavelength $+17 \%$

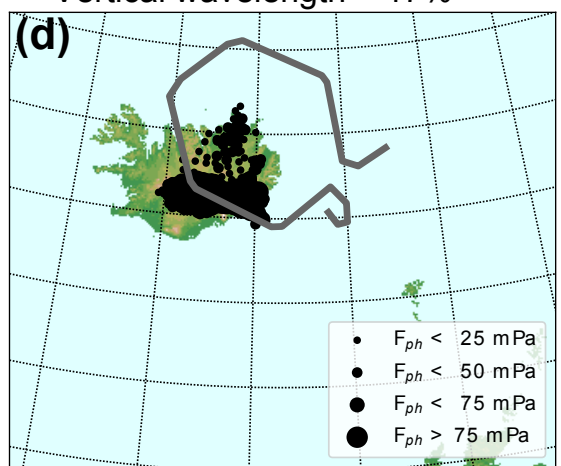

Horizontal wavelength $+15 \%$

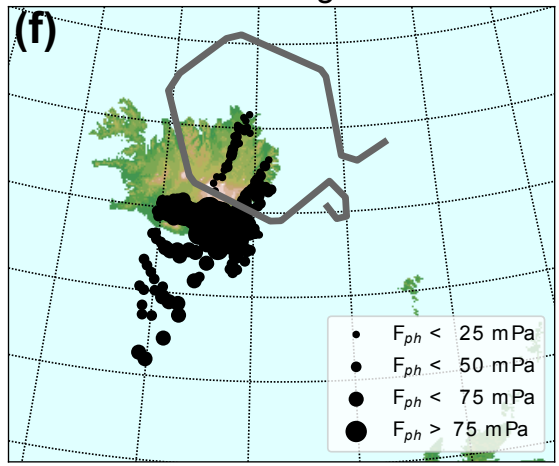

Horizontal direction $+5.5^{\circ}$

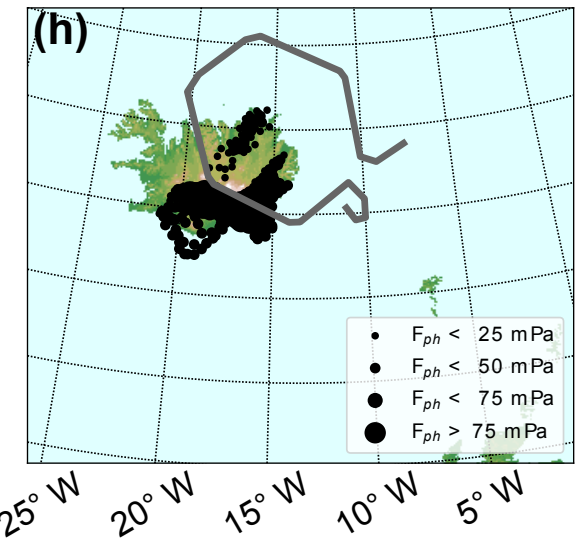

Figure A2. Backward ray tracing with varying input wave parameters. The black dots mark the ray positions at $3 \mathrm{~km}$ altitude. 

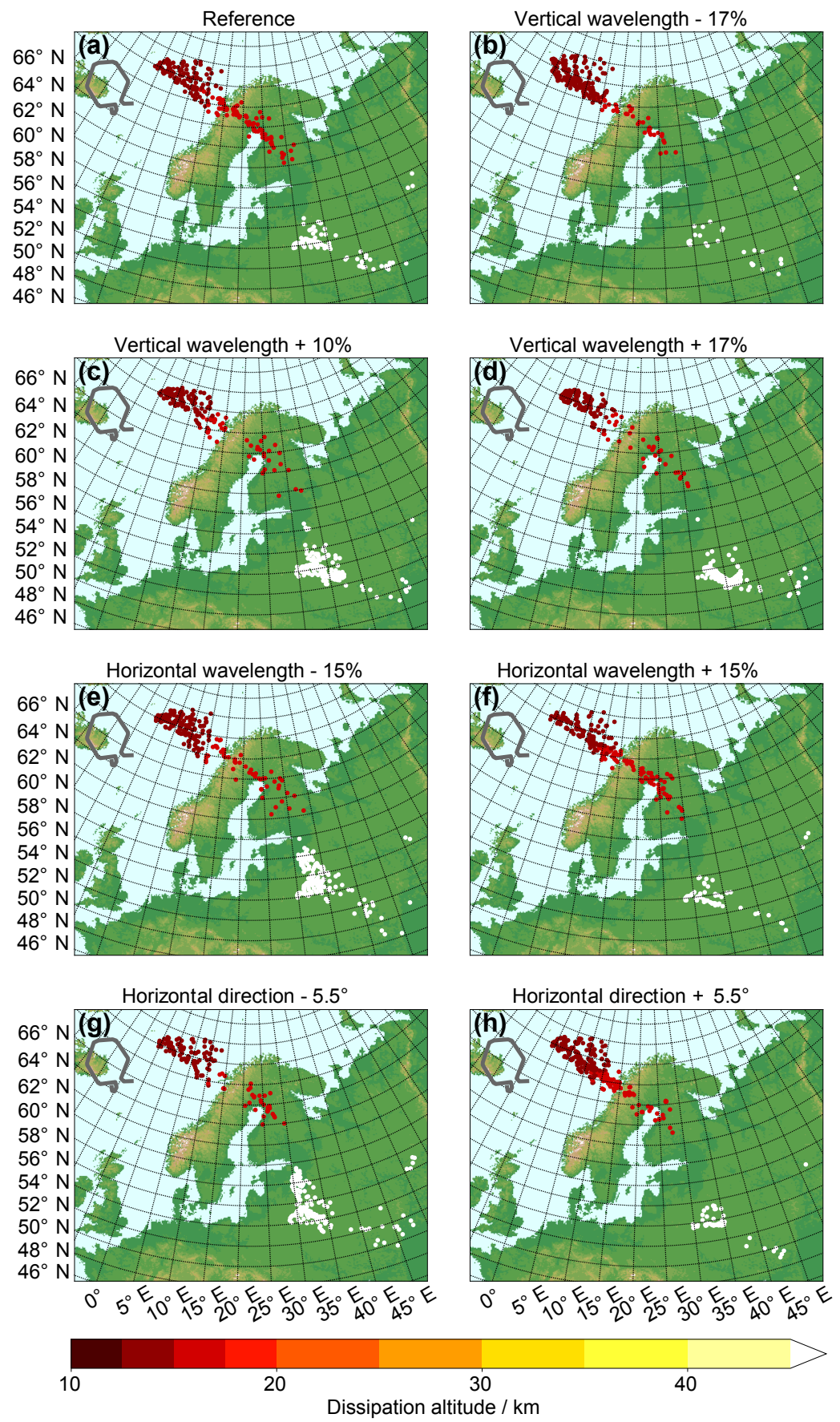

Figure A3. Forward ray tracing with varying input wave parameters. The dots mark the dissipation point of the ray and the color indicates the dissipation height. White dots mark waves which reach the model top at $45 \mathrm{~km}$ altitude. 
Competing interests. The authors declare that they have no conflict of interest.

Special issue statement. This article is part of the special issues "Sources, propagation, dissipation and impact of gravity waves (ACP/AMT inter-journal SI)" and "The Polar Stratosphere in a Changing Climate (POLSTRACC) (ACP/AMT inter-journal SI)". It is not associated with a conference.

Acknowledgements. This work was partly supported by the Bundesministerium für Bildung und Forschung (BMBF) under project 01LG1206C (ROMIC/GW-LCYCLE), as well as by the European Space Agency (ESA) under contract 4000115111/15/NL/FF/ah (GWEX) and the Deutsche Forschungsgemeinschaft (DFG) project PR 919/4-1 (MS-GWaves/SV), which is part of the DFG researchers group FOR 1898 (MS-GWaves). The retrievals were performed on the JURECA supercomputer at the Jülich Supercomputing Center (JSC) as part of the JIEK72 project. The results are based on the efforts of all members of the GLORIA team, including the technology institutes ZEA-1 and ZEA-2 at Forschungszentrum Jülich and the Institute for Data Processing and Electronics at the Karlsruhe Institute of Technology. We would also like to thank the pilots and ground-support team at the Flight Experiments facility of the Deutsches Zentrum für Luft- und Raumfahrt (DLR-FX). Special thanks go to Andreas Diez at DLR-FX for providing the in situ temperature data shown in Fig. 4 and to Corwin Wright at the Centre for Space, Atmospheric and Oceanic Science at University of Bath for providing the plotting code for Fig. 2.

The article processing charges for this open-access

publication were covered by a Research

Centre of the Helmholtz Association.

Edited by: Jörg Gumbel

Reviewed by: Ole Martin Christensen and two anonymous referees

\section{References}

Alexander, M. J. and Dunkerton, T. J.: A Spectral Parameterization of Mean-Flow Forcing due to Breaking Gravity Waves, J. Atmos. Sci., 56, 4167-4182, https://doi.org/10.1175/15200469(1999)056<4167:ASPOMF>2.0.CO;2, 1999.

Alexander, M. J. and Pfister, L.: Gravity wave momentum flux in the lower stratosphere over convection, Geophys. Res. Lett., 22, 2029-2032, https://doi.org/10.1029/95GL01984, 1995.

Alexander, M. J. and Rosenlof, K. H.: Gravity-wave forcing in the stratosphere: Observational constraints from the Upper Atmosphere Research Satellite and implications for parameterization in global models, Geophys. Res. Lett., 108, 4597, https://doi.org/10.1029/2003JD003373, 2003.

Alexander, M. J., Geller, M., McLandress, C., Polavarapu, S., Preusse, P., Sassi, F., Sato, K., Eckermann, S., Ern, M., Hertzog, A., Kawatani, Y., Pulido, M., Shaw, T. A., Sigmond, M., Vincent, R., and Watanabe, S.: Recent developments in gravity-wave effects in climate models and the global distribution of gravitywave momentum flux from observations and models, Q. J. Roy.
Meteor. Soc., 136, 1103-1124, https://doi.org/10.1002/qj.637, 2010.

Amemiya, A. and Sato, K.: A New Gravity Wave Parameterization Including Three-Dimensional Propagation, J. Meteorol. Soc. Jpn. II, 94, 237-256, https://doi.org/10.2151/jmsj.2016-013, 2016.

Beres, J. H., Garcia, R. R., Boville, B. A., and Sassi, F.: Implementation of a gravity wave source spectrum parameterization dependent on the properties of convection in the Whole Atmosphere Community Climate Model (WACCM), J. Geophys. Res.Atmos., 110, D10108, https://doi.org/10.1029/2004JD005504, 2005.

Boccara, G., Hertzog, A., Vincent, R. A., and Vial, F.: Estimation of gravity wave momentum flux and phase speeds from quasi-Lagrangian stratospheric balloon flights. Part I: Theory and simulations, J. Atmos. Sci., 65, 3042-3055, https://doi.org/10.1175/2008JAS2709.1, 2008.

Bossert, K., Fritts, D. C., Pautet, P.-D., Williams, B. P., Taylor, M. J., Kaifler, B., Dörnbrack, A., Reid, I. M., Murphy, D. J., Spargo, A. J., and MacKinnon, A. D.: Momentum flux estimates accompanying multiscale gravity waves over Mount Cook, New Zealand, on 13 July 2014 during the DEEPWAVE campaign, J. Geophys. Res.-Atmos., 120, 9323-9337, https://doi.org/10.1002/2015JD023197, 2015.

Bushell, A. C., Butchart, N., Derbyshire, S. H., Jackson, D. R., Shutts, G. J., Vosper, S. B., and Webster, S.: Parameterized Gravity Wave Momentum Fluxes from Sources Related to Convection and Large-Scale Precipitation Processes in a Global Atmosphere Model, J. Atmos. Sci., 72, 4349-4371, https://doi.org/10.1175/JAS-D-15-0022.1, 2015.

Butchart, N.: The Brewer-Dobson circulation, Rev. Geophys., 52, 157-184, https://doi.org/10.1002/2013RG000448, 2014.

Cao, B., Heale, C. J., Guo, Y., Liu, A. Z., and Snively, J. B.: Observation and modeling of gravity wave propagation through reflection and critical layers above Andes Lidar Observatory at Cerro Pachón, Chile, J. Geophys. Res.-Atmos., 121, 12737-12750, https://doi.org/10.1002/2016JD025173, 2016.

de la Camara, A. and Lott, F.: A parameterization of gravity waves emitted by fronts and jets, Geophys. Res. Lett., 42, 2071-2078, https://doi.org/10.1002/2015GL063298, 2015.

Dunkerton, T.: The role of gravity waves in the quasibiennial oscillation, J. Geophys. Res., 102, 26053-26076, https://doi.org/10.1029/96JD02999, 1997.

Eckermann, S. D. and Vincent, R. A.: Falling sphere observations of anisotropic gravity wave motions in the upper stratosphere over Australia, Pure Appl. Geophys., 130, 509-532, 1989.

Ern, M., Preusse, P., Alexander, M. J., and Warner, C. D.: Absolute values of gravity wave momentum flux derived from satellite data, J. Geophys. Res.-Atmos., 109, D20103, https://doi.org/10.1029/2004JD004752, 2004.

Ern, M., Ploeger, F., Preusse, P., Gille, J. C., Gray, L. J., Kalisch, S., Mlynczak, M. G., Russell III, J. M., and Riese, M.: Interaction of gravity waves with the QBO: A satellite perspective, J. Geophys. Res.-Atmos., 119, 2329-2355, https://doi.org/10.1002/2013JD020731, 2014.

Ern, M., Trinh, Q. T., Kaufmann, M., Krisch, I., Preusse, P., Ungermann, J., Zhu, Y., Gille, J. C., Mlynczak, M. G., Russell III, J. M., Schwartz, M. J., and Riese, M.: Satellite observations of middle atmosphere gravity wave absolute momentum flux and 
of its vertical gradient during recent stratospheric warmings, Atmos. Chem. Phys., 16, 9983-10019, https://doi.org/10.5194/acp16-9983-2016, 2016.

Ern, M., Hoffmann, L., and Preusse, P.: Directional gravity wave momentum fluxes in the stratosphere derived from highresolution AIRS temperature data, Geophys. Res. Lett., 44, 475485, https://doi.org/10.1002/2016GL072007, 2017.

Friedl-Vallon, F., Gulde, T., Hase, F., Kleinert, A., Kulessa, T., Maucher, G., Neubert, T., Olschewski, F., Piesch, C., Preusse, P., Rongen, H., Sartorius, C., Schneider, H., Schönfeld, A., Tan, V., Bayer, N., Blank, J., Dapp, R., Ebersoldt, A., Fischer, H., Graf, F., Guggenmoser, T., Höpfner, M., Kaufmann, M., Kretschmer, E., Latzko, T., Nordmeyer, H., Oelhaf, H., Orphal, J., Riese, M., Schardt, G., Schillings, J., Sha, M. K., Suminska-Ebersoldt, O., and Ungermann, J.: Instrument concept of the imaging Fourier transform spectrometer GLORIA, Atmos. Meas. Tech., 7, 35653577, https://doi.org/10.5194/amt-7-3565-2014, 2014.

Fritts, D. C. and Alexander, M. J.: Gravity wave dynamics and effects in the middle atmosphere, Rev. Geophys., 41, 1003, https://doi.org/10.1029/2001RG000106, 2003.

Fritts, D. C., Smith, R. B., Taylor, M. J., Doyle, J. D., Eckermann, S. D., Doernbrack, A., Rapp, M., Williams, B. P., Pautet, P. D., Bossert, K., Criddle, N. R., Reynolds, C. A., Reinecke, P. A., Uddstrom, M., Revell, M. J., Turner, R., Kaifler, B., Wagner, J. S., Mixa, T., Kruse, C. G., Nugent, A. D., Watson, C. D., Gisinger, S., Smith, S. M., Lieberman, R. S., Laughman, B., Moore, J. J., Brown, W. O., Haggerty, J. A., Rockwell, A., Stossmeister, G. J., Williams, S. F., Hernandez, G., Murphy, D. J., Klekociuk, A. R., Reid, I. M., and Ma, J.: The Deep Propagating Gravity Wave Experiment (DEEPWAVE): An Airborne and Ground-Based Exploration of Gravity Wave Propagation and Effects from Their Sources throughout the Lower and Middle Atmosphere, B. Am. Meteorol. Soc., 97, 425-453, https://doi.org/10.1175/BAMS-D14-00269.1, 2016.

Garcia, R. R., Smith, A. K., Kinnison, D. E., de la Camara, A., and Murphy, D. J.: Modification of the Gravity Wave Parameterization in the Whole Atmosphere Community Climate Model: Motivation and Results, J. Atmos. Sci., 74, 275-291, https://doi.org/10.1175/JAS-D-16-0104.1, 2017.

Geller, M. A., Alexander, M. J., Love, P. T., Bacmeister, J., Ern, M., Hertzog, A., Manzini, E., Preusse, P., Sato, K., Scaife, A. A., and Zhou, T.: A comparison between gravity wave momentum fluxes in observations and climate models, J. Climate, 26, 6383-6405, https://doi.org/10.1175/JCLI-D-12-00545.1, 2013.

Gerrard, A. J., Kane, T. J., Eckermann, S. D., and Thayer, J. P.: Gravity waves and mesospheric clouds in the summer middle atmosphere: A comparison of lidar measurements and ray modeling of gravity waves over Sonderstrom, Greenland, J. Geophys. Res., 109, D10103, https://doi.org/10.1029/2002JD002783, 2004.

Guest, F., Reeder, M., Marks, C., and Karoly, D.: Inertia-gravity waves observed in the lower stratosphere over Macquarie Island, J. Atmos. Sci., 57, 737-752, 2000.

Hertzog, A., Boccara, G., Vincent, R. A., Vial, F., and Coquerez, P.: Estimation of gravity-wave momentum flux and phase speeds from long-duration stratospheric balloon flights. 2: Results from the Vorcore campaign in Antarctica, J. Atmos. Sci., 65, 30563070, https://doi.org/10.1175/2008JAS2710.1, 2008.
Hertzog, A., Alexander, M. J., and Plougonven, R.: On the Intermittency of Gravity Wave Momentum Flux in the Stratosphere, J. Atmos. Sci., 69, 3433-3448, https://doi.org/10.1175/JAS-D-1209.1, 2012.

Hines, C. O.: Doppler-spread parameterization of gravity-wave momentum deposition in the middle atmosphere. Part 1: Basic formulation, J. Atmos. Sol.-Terr. Phy., 59, 371-386, https://doi.org/10.1016/S1364-6826(96)00079-X, 1997.

Holton, J. R.: The role of gravity wave induced drag and diffusion on the momentum budget of the mesosphere, J. Atmos. Sci., 39, 791-799, 1982.

Holton, J. R.: The Influence of Gravity Wave Breaking on the General Circulation of the Middle Atmosphere, J. Atmos. Sci., 40, 2497-2507, https://doi.org/10.1175/15200469(1983)040<2497:TIOGWB>2.0.CO;2, 1983.

Kalisch, S., Preusse, P., Ern, M., Eckermann, S. D., and Riese, M.: Differences in gravity wave drag between realistic oblique and assumed vertical propagation, J. Geophys. Res.-Atmos., 119, 10081-10099, https://doi.org/10.1002/2014JD021779, 2014.

Kaufmann, M., Blank, J., Guggenmoser, T., Ungermann, J., Engel, A., Ern, M., Friedl-Vallon, F., Gerber, D., Grooß, J. U., Guenther, G., Höpfner, M., Kleinert, A., Kretschmer, E., Latzko, Th., Maucher, G., Neubert, T., Nordmeyer, H., Oelhaf, H., Olschewski, F., Orphal, J., Preusse, P., Schlager, H., Schneider, H., Schuettemeyer, D., Stroh, F., Suminska-Ebersoldt, O., Vogel, B., M. Volk, C., Woiwode, W., and Riese, M.: Retrieval of threedimensional small-scale structures in upper-tropospheric/lowerstratospheric composition as measured by GLORIA, Atmos. Meas. Tech., 8, 81-95, https://doi.org/10.5194/amt-8-81-2015, 2015.

Kawatani, Y., Sato, K., Dunkerton, T. J., Watanabe, S., Miyahara, S., and Takahashi, M.: The roles of equatorial trapped waves and three-dimensionally propagating gravity waves in driving the quasibiennial oscillation. Part I: zonal mean wave forcing, J. Atmos. Sci., 67, 963-980, https://doi.org/10.1175/2009JAS3222.1, 2010.

Kidston, J., Scaife, A. A., Hardiman, S. C., Mitchell, D. M., Butchart, N., Baldwin, M. P., and Gray, L. J.: Stratospheric influence on tropospheric jet streams, storm tracks and surface weather, Nat. Geosci., 8, 433-440, https://doi.org/10.1038/ngeo2424, 2015.

Kim, Y. H., Bushell, A. C., Jackson, D. R., and Chun, H. Y.: Impacts of introducing a convective gravity-wave parameterization upon the QBO in the Met Office Unified Model, Geophys. Res. Lett., 40, 1873-1877, https://doi.org/10.1002/grl.50353, 2013.

Krisch, I.: Tomographic Observation of a Gravity Wave Event above Iceland on 25 January 2016, https://doi.org/10.5446/31482, 2017a.

Krisch, I.: F10_20160125_GLORIA_dynamics_mode_tomography _FZJ.nc, Forschungszentrum Jülich $\mathrm{GmbH}$, available at: https://halo-db.pa.op.dlr.de/dataset/5079, last access: 10 July $2017 b$.

Lehmann, C. I., Kim, Y.-H., Preusse, P., Chun, H.-Y., Ern, M., and Kim, S.-Y.: Consistency between Fourier transform and smallvolume few-wave decomposition for spectral and spatial variability of gravity waves above a typhoon, Atmos. Meas. Tech., 5, 1637-1651, https://doi.org/10.5194/amt-5-1637-2012, 2012.

Lu, X., Chen, C., Huang, W., Smith, J. A., Chu, X., Yuan, T., Pautet, P.-D., Taylor, M. J., Jie, G., and Cullens, C. Y.: A co- 
ordinated study of $1 \mathrm{~h}$ mesoscale gravity waves propagating from Logan to Boulder with CRRL Na Doppler lidars and temperature mapper, J. Geophys. Res.-Atmos., 120, 10006-10021, https://doi.org/10.1002/2015JD023604, 2015.

Marks, C. J. and Eckermann, S. D.: A Three-Dimensional Nonhydrostatic Ray-Tracing Model for Gravity Waves: Formulation and Preliminary Results for the Middle Atmosphere, J. Atmos. Sci., 52, 1959-1984, https://doi.org/10.1175/15200469(1995)052<1959:ATDNRT>2.0.CO;2, 1995.

McFarlane, N.: The Effect of Orographically Excited Gravity Wave Drag on the General Circulation of the Lower Stratosphere and Troposphere, J. Atmos. Sci., 44, 1775-1800, 1987.

McLandress, C.: On the importance of gravity waves in the middle atmosphere and their parameterization in general circulation models, J. Atmos. Sol.-Terr. Phy., 60, 1357-1383, https://doi.org/10.1016/S1364-6826(98)00061-3, 1998.

McLandress, C., Shepherd, T. G., Polavarapu, S., and Beagley, S. R.: Is Missing Orographic Gravity Wave Drag near $60^{\circ} \mathrm{S}$ the Cause of the Stratospheric Zonal Wind Biases in Chemistry-Climate Models?, J. Atmos. Sci., 69, 802-818, https://doi.org/10.1175/JAS-D-11-0159.1, 2012.

Podglajen, A., Hertzog, A., Plougonven, R., and Legras, B.: Lagrangian temperature and vertical velocity fluctuations due to gravity waves in the lower stratosphere, Geophys. Res. Lett., 43, 3543-3553, https://doi.org/10.1002/2016GL068148, 2016.

Pramitha, M., Venkat Ratnam, M., Taori, A., Krishna Murthy, B. V., Pallamraju, D., and Vijaya Bhaskar Rao, S.: Evidence for tropospheric wind shear excitation of high-phase-speed gravity waves reaching the mesosphere using the ray-tracing technique, Atmos. Chem. Phys., 15, 2709-2721, https://doi.org/10.5194/acp15-2709-2015, 2015.

Preusse, P., Eckermann, S. D., Ern, M., Oberheide, J., Picard, R. H., Roble, R. G., Riese, M., Russell III, J. M., and Mlynczak, M. G.: Global ray tracing simulations of the SABER gravity wave climatology, J. Geophys. Res.-Atmos., 114, D08126, https://doi.org/10.1029/2008JD011214, 2009.

Preusse, P., Ern, M., Bechtold, P., Eckermann, S. D., Kalisch, S., Trinh, Q. T., and Riese, M.: Characteristics of gravity waves resolved by ECMWF, Atmos. Chem. Phys., 14, 10483-10508, https://doi.org/10.5194/acp-14-10483-2014, 2014.

Ribstein, B. and Achatz, U.: The interaction between gravity waves and solar tides in a linear tidal model with a 4-D ray-tracing gravity-wave parameterization, J. Geophys. Res.-Space, 121, 8936-8950, https://doi.org/10.1002/2016JA022478, 2016.

Richter, J. H., Sassi, F., and Garcia, R. R.: Toward a Physically Based Gravity Wave Source Parameterization in a General Circulation Model, J. Atmos. Sci., 67, 136-156, https://doi.org/10.1175/2009JAS3112.1, 2010.

Riese, M., Spang, R., Preusse, P., Ern, M., Jarisch, M., Offermann, D., and Grossmann, K. U.: Cryogenic Infrared Spectrometers and Telescopes for the Atmosphere (CRISTA) data processing and atmospheric temperature and trace gas retrieval, J. Geophys. Res.-Atmos., 104, 16349-16367, https://doi.org/10.1029/1998JD100057, 1999.

Riese, M., Oelhaf, H., Preusse, P., Blank, J., Ern, M., Friedl-Vallon, F., Fischer, H., Guggenmoser, T., Höpfner, M., Hoor, P., Kaufmann, M., Orphal, J., Plöger, F., Spang, R., Suminska-Ebersoldt, O., Ungermann, J., Vogel, B., and Woiwode, W.: Gimballed Limb Observer for Radiance Imaging of the Atmosphere (GLO-
RIA) scientific objectives, Atmos. Meas. Tech., 7, 1915-1928, https://doi.org/10.5194/amt-7-1915-2014, 2014.

Sandu, I., Bechtold, P., Beljaars, A., Bozzo, A., Pithan, F., Shepherd, T. G., and Zadra, A.: Impacts of parameterized orographic drag on the Northern Hemisphere winter circulation, J. Adv. Model. Earth Syst., 8, 196-211, https://doi.org/10.1002/2015MS000564, 2016.

Sato, K., Watanabe, S., Kawatani, Y., Tomikawa, Y., Miyazaki, K., and Takahashi, M.: On the origins of mesospheric gravity waves, Geophys. Res. Lett., 36, L19801, https://doi.org/10.1029/2009GL039908, 2009.

Savitzky, A. and Golay, M. J. E.: Smoothing and Differentiation of Data by Simplified Least Squares Procedures, Anal. Chem., 36, 1627-1639, https://doi.org/10.1021/ac60214a047, 1964.

Scaife, A. A., Karpechko, A. Y., Baldwin, M. P., Brookshaw, A., Butler, A. H., Eade, R., Gordon, M., MacLachlan, C., Martin, N., Dunstone, N., and Smith, D.: Seasonal winter forecasts and the stratosphere, Atmos. Sci. Lett., 17, 51-56, https://doi.org/10.1002/asl.598, 2016.

Scinocca, J. F. and McFarlane, N. A.: The parametrization of drag induced by stratified flow over anisotropic orography, Q. J. Roy. Meteor. Soc., 126, 2353-2393, https://doi.org/10.1002/qj.49712656802, 2000.

Sigmond, M. and Scinocca, J. F.: The Influence of the Basic State on the Northern Hemisphere Circulation Response to Climate Change, J. Climate, 23, 1434-1446, https://doi.org/10.1175/2009JCLI3167.1, 2010.

Siskind, D. E.: Simulations of the winter stratopause and summer mesopause at varying spatial resolutions, J. Geophys. Res.Atmos., 119, 461-470, https://doi.org/10.1002/2013JD020985, 2014.

Smith, R. B., Nugent, A. D., Kruse, C. G., Fritts, D. C., Doyle, J. D., Eckermann, S. D., Taylor, M. J., Doernbrack, A., Uddstrom, M., Cooper, W., Romashkin, P., Jensen, J., and Beaton, S.: Stratospheric Gravity Wave Fluxes and Scales during DEEPWAVE, J. Atmos. Sci., 73, 2851-2869, https://doi.org/10.1175/JAS-D-150324.1, 2016.

Stober, G., Sommer, S., Rapp, M., and Latteck, R.: Investigation of gravity waves using horizontally resolved radial velocity measurements, Atmos. Meas. Tech., 6, 2893-2905, https://doi.org/10.5194/amt-6-2893-2013, 2013.

Ungermann, J., Kaufmann, M., Hoffmann, L., Preusse, P., Oelhaf, H., Friedl-Vallon, F., and Riese, M.: Towards a 3-D tomographic retrieval for the air-borne limb-imager GLORIA, Atmos. Meas. Tech., 3, 1647-1665, https://doi.org/10.5194/amt-3-1647-2010, 2010.

Ungermann, J., Blank, J., Lotz, J., Leppkes, K., Hoffmann, L., Guggenmoser, T., Kaufmann, M., Preusse, P., Naumann, U., and Riese, M.: A 3-D tomographic retrieval approach with advection compensation for the air-borne limb-imager GLORIA, Atmos. Meas. Tech., 4, 2509-2529, https://doi.org/10.5194/amt-4-25092011, 2011.

Ungermann, J., Blank, J., Dick, M., Ebersoldt, A., Friedl-Vallon, F., Giez, A., Guggenmoser, T., Höpfner, M., Jurkat, T., Kaufmann, M., Kaufmann, S., Kleinert, A., Krämer, M., Latzko, T., Oelhaf, H., Olchewski, F., Preusse, P., Rolf, C., Schillings, J., Suminska-Ebersoldt, O., Tan, V., Thomas, N., Voigt, C., Zahn, A., Zöger, M., and Riese, M.: Level 2 processing for the imaging Fourier transform spectrometer GLORIA: derivation and val- 
idation of temperature and trace gas volume mixing ratios from calibrated dynamics mode spectra, Atmos. Meas. Tech., 8, 24732489, https://doi.org/10.5194/amt-8-2473-2015, 2015.

Wagner, J., Dörnbrack, A., Rapp, M., Gisinger, S., Ehard, B., Bramberger, M., Witschas, B., Chouza, F., Rahm, S., Mallaun, C., Baumgarten, G., and Hoor, P.: Observed versus simulated mountain waves over Scandinavia - improvement of vertical winds, energy and momentum fluxes by enhanced model resolution?, Atmos. Chem. Phys., 17, 4031-4052, https://doi.org/10.5194/acp-17-4031-2017, 2017.

Wang, L. and Geller, M. A.: Morphology of gravity-wave energy as observed from 4 years (1998-2001) of high vertical resolution U.S. radiosonde data, J. Geophys. Res., 108, 4489, https://doi.org/10.1029/2002JD002786, 2003.

Wright, C. J., Hindley, N. P., Hoffmann, L., Alexander, M. J., and Mitchell, N. J.: Exploring gravity wave characteristics in 3-D using a novel S-transform technique: AIRS/Aqua measurements over the Southern Andes and Drake Passage, Atmos. Chem. Phys., 17, 8553-8575, https://doi.org/10.5194/acp17-8553-2017, 2017.
Xu, X., Wang, Y., Xue, M., and Zhu, K.: Impacts of Horizontal Propagation of Orographic Gravity Waves on the Wave Drag in the Stratosphere and Lower Mesosphere, J. Geophys. Res.-Atmos., 122, 11301-11312, https://doi.org/10.1002/2017JD027528, 2017.

Zhang, S. D., Huang, C. M., Huang, K. M., Yi, F., Zhang, Y. H., Gong, Y., and Gan, Q.: Spatial and seasonal variability of medium- and high-frequency gravity waves in the lower atmosphere revealed by US radiosonde data, Ann. Geophys., 32, 1129-1143, https://doi.org/10.5194/angeo-32-1129-2014, 2014. 